\title{
Nanowires-assembled $\mathrm{WO}_{3}$ nanomesh for fast detection of ppb-level $\mathrm{NO}_{2}$ at low temperature
}

\author{
Di LIU, Xiaowei REN, Yesheng LI, Zilong TANG*, Zhongtai ZHANG \\ State Key Laboratory of New Ceramics and Fine Processing, School of Materials Science and \\ Engineering, Tsinghua University, Beijing 100084, China
}

Received: May 7, 2019; Revised: July 14, 2019; Accepted: July 15, 2019

(C) The Author(s) 2019.

\begin{abstract}
Hierarchical $\mathrm{WO}_{3}$ nanomesh, assembled from single-crystalline $\mathrm{WO}_{3}$ nanowires, is prepared via a hydrothermal method using thiourea $(\mathrm{Tu})$ as the morphology-controlling agent. Formation of the hierarchical architecture comprising of $\mathrm{WO}_{3}$ nanowires takes place via Ostwald ripening mechanism with the growth orientation. The sensor based on $\mathrm{WO}_{3}$ nanomesh has good electrical conductivity and is therefore suitable as $\mathrm{NO}_{2}$ sensing material. The $\mathrm{WO}_{3}$ nanomesh sensor exhibited high response, short response and recovery time, and excellent selectivity towards ppb-level $\mathrm{NO}_{2}$ at low temperature of $160{ }^{\circ} \mathrm{C}$. The superior gas performance of the sensor was attributed to the high-purity hexagonal $\mathrm{WO}_{3}$ with high specific surface area, which gives rise to enhanced surface adsorption sites for gas adsorption. The electron depletion theory was used for explaining the $\mathrm{NO}_{2}$-sensing mechanism by the gas adsorption/desorption and charge transfer happened on the surface of $\mathrm{WO}_{3}$ nanomesh.
\end{abstract}

Keywords: $\mathrm{WO}_{3}$ nanomesh; controlling agent; $\mathrm{NO}_{2}$ sensing; charge transfer

\section{Introduction}

$\mathrm{NO}_{2}$, as one of the most toxic and harmful gases in the atmosphere, is the precursor of acid rain and photochemical smog. It is generated by the fuel burning and has caused a seriously harmful effect to the living environment [1,2]. Thus, the development of $\mathrm{NO}_{2}$ gas sensors with high sensitivity and low detect limitation is urgently necessary. At present, metal oxide semiconductors with various nanostructures, such as $\mathrm{SnO}_{2}$ [3-5], $\mathrm{ZnO}[6,7], \mathrm{WO}_{3}[8,9]$, and $\mathrm{TiO}_{2}$ [10], have been well investigated to detect $\mathrm{NO}_{2}$ owing to their low cost, simple operation, and nontoxic nature. Among them, tungsten oxide, a n-type semiconductor with wide bandgap

* Corresponding author.

E-mail: tzl@tsinghua.edu.cn
(2.6-3.2 eV), has been considered as a promising sensing material for the detection of $\mathrm{NO}_{2}$ because of its low cost, high sensitivity, and good repeatability [11-13]. However, the operating temperature of $\mathrm{WO}_{3}$ gas sensors is usually above $200{ }^{\circ} \mathrm{C}$ due to the poor electrical conductivity of some $\mathrm{WO}_{3}$ nanostructures [14-16]. For example, $\mathrm{WO}_{3}$ nanoparticles synthesized by spark ablation were required to detect $\mathrm{NO}_{2}$ gas at a high operating temperature of $200{ }^{\circ} \mathrm{C}$ due to their high electrical resistance [15]. Triple-shelled $\mathrm{WO}_{3}$ spheres synthesized by ultrasonic spray pyrolysis showed a large resistance $\left(>1 \mathrm{G} \Omega\right.$ ) when exposed to $\mathrm{NO}_{2}$ gas at low operating temperature [16]. A general strategy to solve this problem is surface functionalization with noble metals $(\mathrm{Au}, \mathrm{Ag}$, and $\mathrm{Pt}$ ) $[8,17-20]$. Gao's group reported Ag-loaded mesoporous $\mathrm{WO}_{3}$ showed excellent response to $\mathrm{NO}_{2}$ at $75{ }^{\circ} \mathrm{C}$ [17]. Recently, Zhao et al. [8] reported Au@WO $\mathrm{WO}_{3}$ 
core-shell nanospheres showed an improvement in $\mathrm{NO}_{2}$ sensing performance in terms of sensitivity, response/ recovery rate, and detection limit at $100{ }^{\circ} \mathrm{C}$. However, the method is not always effective, because the noble metal particles tend to catalytic poisoning and noble metal modification increases the fabricating cost [21]. Another way to achieve this is to increase their surfaceto-volume ratio by preparing hierarchical nanostructures. Hierarchical $\mathrm{WO}_{3}$ nanostructures can increase the active adsorption sites for $\mathrm{NO}_{2}$ molecules and these thin structural units can provide efficient electron transport pathways [22]. Many techniques have been used to synthesize $\mathrm{WO}_{3}$ in various forms and investigate the effect of morphology on their gas-sensing performance. Various morphologies of $\mathrm{WO}_{3}$, such as nanofibers, nanoflowers, and nanoplates, have been prepared by a variety of methods including electrospinning, thermal evaporation, and hydrothermal and plasma spraying [23-27]. Compared to other synthetic techniques, hydrothermal method is more advantageous due to low-temperature synthesis and ease of mass production [28-32].

In this work, hierarchical tungsten trioxide nanomesh assembled by single-crystalline nanowires was fabricated via a facile hydrothermal method using thiourea $(\mathrm{Tu})$ as the morphology-directing agent. Hexagonal $\mathrm{WO}_{3}$ nanomesh has good electrical conductivity owing to the assembled nanowires promoting electron transport. The as-prepared $\mathrm{WO}_{3}$ nanomesh exhibited high sensibility, short response and recovery time, and good sensing selectivity to $\mathrm{NO}_{2}$ at a relatively low working temperature of $160{ }^{\circ} \mathrm{C}$. Such excellent performance can be attributed to the highly exposed surface area, which propels the interaction between $\mathrm{NO}_{2}$ gas and sensing element. The sensing mechanism is explained in terms of the gas adsorption/desorption and electron transport between gas molecules and $\mathrm{WO}_{3}$ nanomesh.

\section{Experimental}

\section{1 Materials}

Hydrogen peroxide solution $\left(\mathrm{H}_{2} \mathrm{O}_{2}\right.$, analytical reagent, $30 \mathrm{wt} \%$ in $\mathrm{H}_{2} \mathrm{O}$ ) was obtained from Sigma-Aldrich Corporation (Shanghai, China). Tungstic acid $\left(\mathrm{H}_{2} \mathrm{WO}_{4}\right.$, guarantee reagent), $\mathrm{Tu}\left(\mathrm{CH}_{4} \mathrm{~N}_{2} \mathrm{~S}\right.$, analytical reagent), and ethanol absolute $\left(\mathrm{C}_{2} \mathrm{H}_{6} \mathrm{O}\right.$, analytical reagent) were purchased from Sinopharm Chemical Reagent Co., Ltd., China. Deionized water was used for all experiments.

\section{2 Synthesis of $\mathrm{WO}_{3}$ nanomesh}

In a typical procedure, $1.25 \mathrm{~g}$ tungstic acid was dissolved in $25 \mathrm{~mL}$ hydrogen peroxide solution heated in water bath at $90{ }^{\circ} \mathrm{C}$ with magnetic stirring. After stirring for $1 \mathrm{~h}$ and $20 \mathrm{~min}$, the above solution was diluted to $60 \mathrm{~mL}$ with deionized water, then taking $42 \mathrm{~mL}$ of diluted solution and adding $168 \mathrm{~mL}$ deionized water and $14 \mathrm{~mL}$ $\mathrm{HCl}(3 \mathrm{~mol} / \mathrm{L})$ into above diluted solution. Next, Tu with different weight was added to above solution to achieve different concentration $(0,0.05,0.1$, and $0.2 \mathrm{M})$, followed by magnetic stirring for $20 \mathrm{~min}$ forming a suspension solution. Next, $30 \mathrm{~mL}$ of above solution was taken to $50 \mathrm{~mL}$ teflon-lined stainless steel autoclave. After heating in an electric oven at $180{ }^{\circ} \mathrm{C}$ for $12 \mathrm{~h}$, the autoclave was naturally cooled down. The product was obtained by filtration, washed with enough deionized water and absolute ethanol, and dried under vacuum at $60{ }^{\circ} \mathrm{C}$ overnight. The as-prepared product was subsequently annealed in air at $300{ }^{\circ} \mathrm{C}$ for $2 \mathrm{~h}$ to improve the crystallinity.

\section{3 Characterizations}

The powder X-ray diffraction (XRD) patterns were recorded on a Rigaku D/max-V2500 diffractometer with $\mathrm{Cu} \mathrm{K} \alpha$ radiation. Scanning electron microscopy (SEM) and transmission electron microscopy (TEM) images were obtained with scanning electron microscope (SEM, Zeiss, Germany) and transmission electron microscope (TEM, JEM-2100F, Japan), respectively. X-ray photoelectron spectroscopy (XPS) was recorded with an ESCALAB 250Xi instrument (Thermo Fisher Scientific, USA). Raman spectra were carried out on a LabRAM HR800 Raman spectrometer with $632.8 \mathrm{~nm}$ laser radiation. The Brunauer-Emmett-Teller (BET) surface area and Barrett-Joyner-Halenda (BJH) pore sizeand pore distribution were analyzed by nitrogen adsorption using an American Contador QuadraSorb SI-MP instrument. The current-voltage $(I-V)$ characteristics of the sensors were measured using an electrochemical workstation (CHI-660E, China).

\section{4 Fabrication and measurement of gas sensors}

The annealed powder sample was placed in an agate mortar and thoroughly ground after adding an appropriate amount of ethanol. The obtained sensing slurry was deposited on the cleaned Au interdigital electrodes by a thin brush. Then, the electrodes with sensing film were dried at $70{ }^{\circ} \mathrm{C}$ in air for $12 \mathrm{~h}$. The gas-sensing properties 
of the electrodes were measured in a computer-controlled gas-sensing testing system consisting of mass flow controllers (MFC, Beijing Qixing Co., Ltd., China), a test chamber with a heating plate, and a data-acquisition system. The electrical resistances of the sensors were recorded by a digital multimeter (Agilent 34465A), and the upper limit of the digital multimeter is $1.2 \mathrm{G} \Omega$. The test $\mathrm{NO}_{2}$ gas was mixed by 10 ppm $\mathrm{NO}_{2}$ (Beijing AP BAIF Gases Industry Co., Ltd., China) and background gas. The flow rates of $10 \mathrm{ppm} \mathrm{NO}_{2}$ and background gas were controlled using mass flow controllers. The total gas flow rate was fixed at $200 \mathrm{~mL} / \mathrm{min}$. The desired gas concentration is determined by the multiple of the $\mathrm{NO}_{2}$ gas diluted by background gas. The sensor response was defined as $R_{\mathrm{g}} / R_{\mathrm{a}}$ for oxidizing gas or $R_{\mathrm{a}} / R_{\mathrm{g}}$ for reducing gas, where $R_{\mathrm{g}}$ and $R_{\mathrm{a}}$ are the resistances of the sensor in targeted gas and in air, respectively. The response and recovery time were defined as the time taken by the sensor to achieve $90 \%$ of the total resistance change.

\section{Results and discussion}

\section{1 Material characteristics}

The crystal structure of the samples synthesized in precursor with different concentration Tu after heating treatment at $300{ }^{\circ} \mathrm{C}$ for $2 \mathrm{~h}$ was confirmed by XRD as illustrated in Fig. 1. The main diffraction peaks of the sample synthesized without adding Tu can be well indexed to the orthorhombic phase $\mathrm{WO}_{3} \cdot 0.33 \mathrm{H}_{2} \mathrm{O}$ (JCPDS No. 54-1012). With the increase of precursor $\mathrm{Tu}$ concentration, the diffraction intensity of the (111) peak for the orthorhombic $\mathrm{WO}_{3} \cdot 0.33 \mathrm{H}_{2} \mathrm{O}$ gradually decreases. When the sample is prepared in precursor with a $\mathrm{Tu}$ concentration of $0.2 \mathrm{M}$, the (111) peak for the orthorhombic $\mathrm{WO}_{3} \cdot 0.33 \mathrm{H}_{2} \mathrm{O}$ disappears and the main diffraction peaks can well correspond to the hexagonal phase $\mathrm{WO}_{3}$ (JCPDS No. 85-2460). It is worth noting that the crystalline phase of the sample can be adjusted by the concentration of $\mathrm{Tu}$ in the precursor from the XRD results.

The morphology and microstructure of the samples after heating treatment at $300{ }^{\circ} \mathrm{C}$ for $2 \mathrm{~h}$ were examined by SEM measurement. As shown in Fig. 2(a), the sample

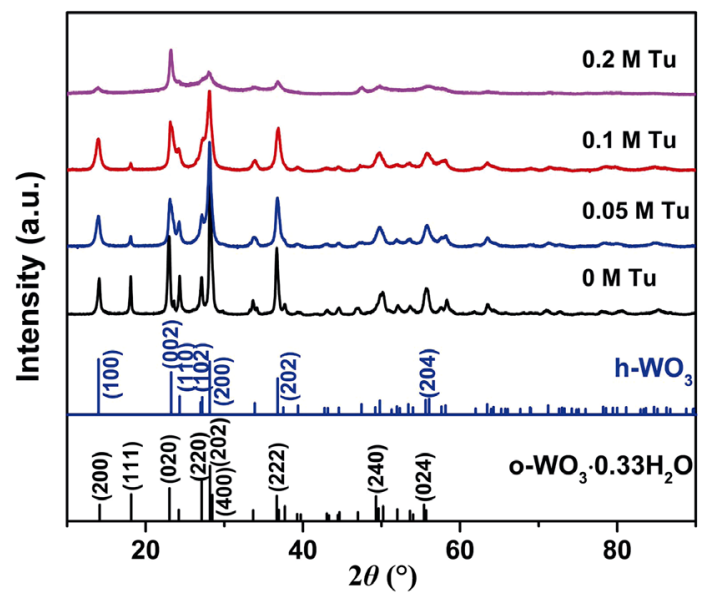

Fig. 1 XRD patterns of samples prepared in precursor with $\mathrm{Tu}$ concentration of $0,0.05,0.1$, and $0.2 \mathrm{M}$.
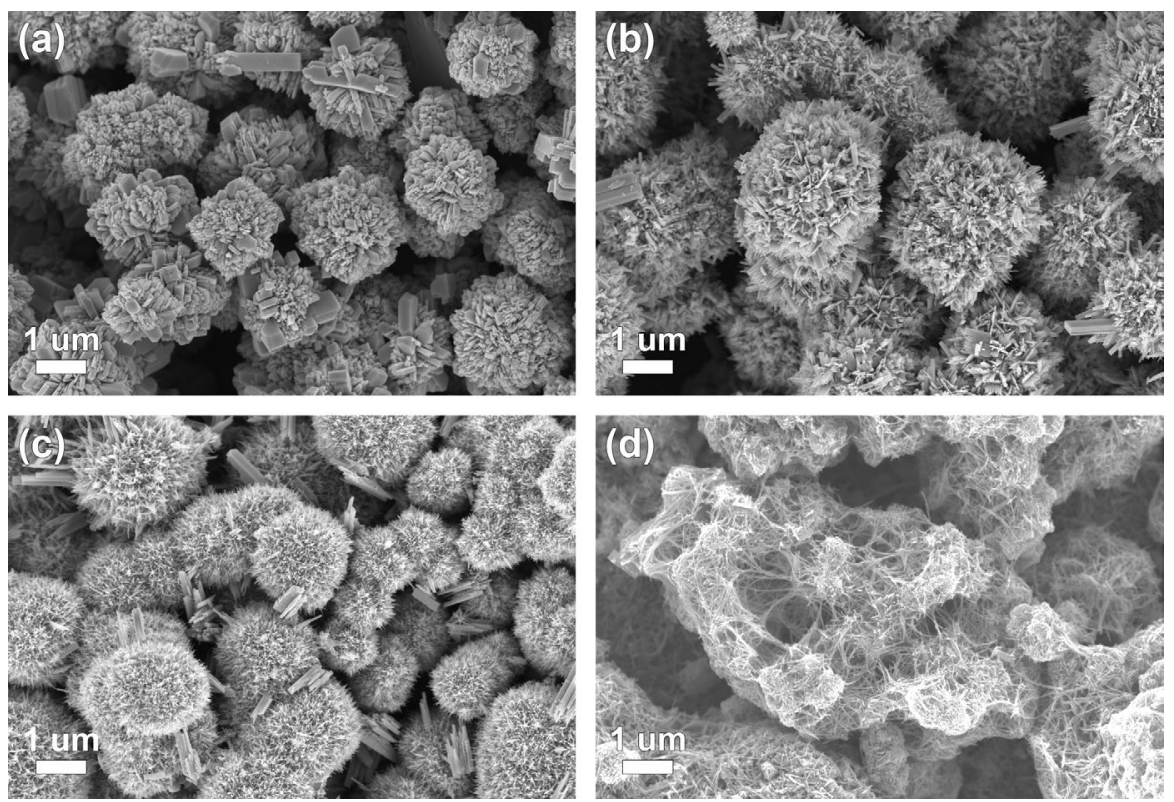

Fig. 2 SEM images of samples prepared in precursor with Tu concentration of 0, 0.05, 0.1, and 0.2 M. 
synthesized in precursor without Tu consists of micronlevel flowers assembled with rectangular blocks. As shown in Fig. 2(b), the sample synthesized in precursor with $0.05 \mathrm{M} \mathrm{Tu}$ consists of micron-level flowers assembled with rectangular sheets. As shown in Fig. 2(c), the sample synthesized in precursor with $0.1 \mathrm{M} \mathrm{Tu}$ consists of urchin-shaped spheres assembled with needlelike units. As shown in Fig. 2(d), the sample synthesized in precursor with $0.2 \mathrm{M}$ Tu consists of nanomesh assembled with nanowires. It is worth noting that the morphologies and microstructure of the samples can be adjusted by the concentrations of Tu in the precursor from the SEM results. Therefore, Tu, an anionic surfactant, acted as a structure-directing agent in the process of aggregation as well as a morphologydirecting agent by confining crystal growth in certain directions.

The $I-V$ curves of the sensing devices based on annealed samples that were synthesized in precursor with $0.05,0.1$, and $0.2 \mathrm{M} \mathrm{Tu}$ were recorded by an electrochemical workstation. Figure 3 shows the $I-V$ curves of the sensors measured from -5 to $+5 \mathrm{~V}$ to investigate the electrical contact between the sensing material and the $\mathrm{Au}$ interdigital electrodes in air at room temperature $\left(25 \pm 5^{\circ} \mathrm{C}\right)$. When the voltage increases, the current also increases linearly suggesting good electrical contact between the sensing material and electrodes. As shown in Fig. 3, the resistances of sensors based on annealed samples that were synthesized in precursor with $0.05,0.1$, and $0.2 \mathrm{M}$ Tu could be calculated to be 424,28 , and $3 \mathrm{M} \Omega$, respectively. The resistances of the sensing devices based on annealed samples decrease sharply with the increase of the concentration of $\mathrm{Tu}$ in precursor. The sensing device based on the annealed sample synthesized in precursor with $0.2 \mathrm{M}$ Tu exhibits linear ohmic behavior and the best electrical conductivity. As a result, the annealed sample synthesized in precursor with $0.2 \mathrm{M} \mathrm{Tu}$ was selected as sensing material in the following characterization and gas sensing tests.

The high-magnification SEM and TEM images of the annealed sample synthesized in precursor with $0.2 \mathrm{M}$ Tu are shown in Fig. 4. As shown in Figs. 4(a) and 4(b),

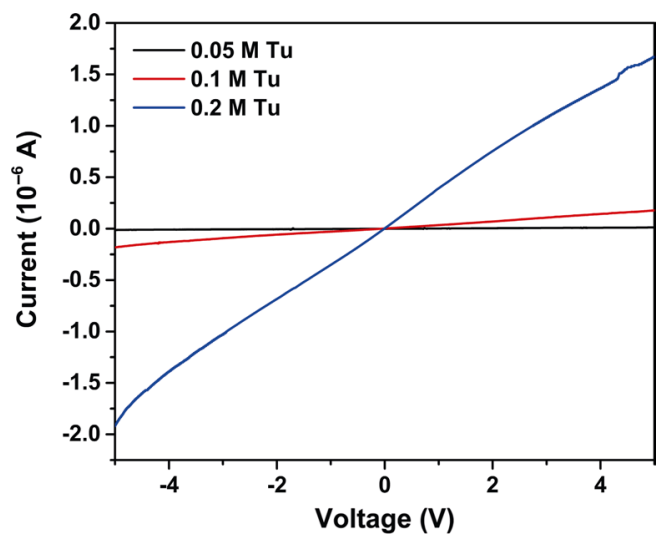

Fig. $3 \quad I-V$ characteristics of the sensors based on samples prepared in precursor with Tu concentration of $0.05,0.1$, and $0.2 \mathrm{M}$.
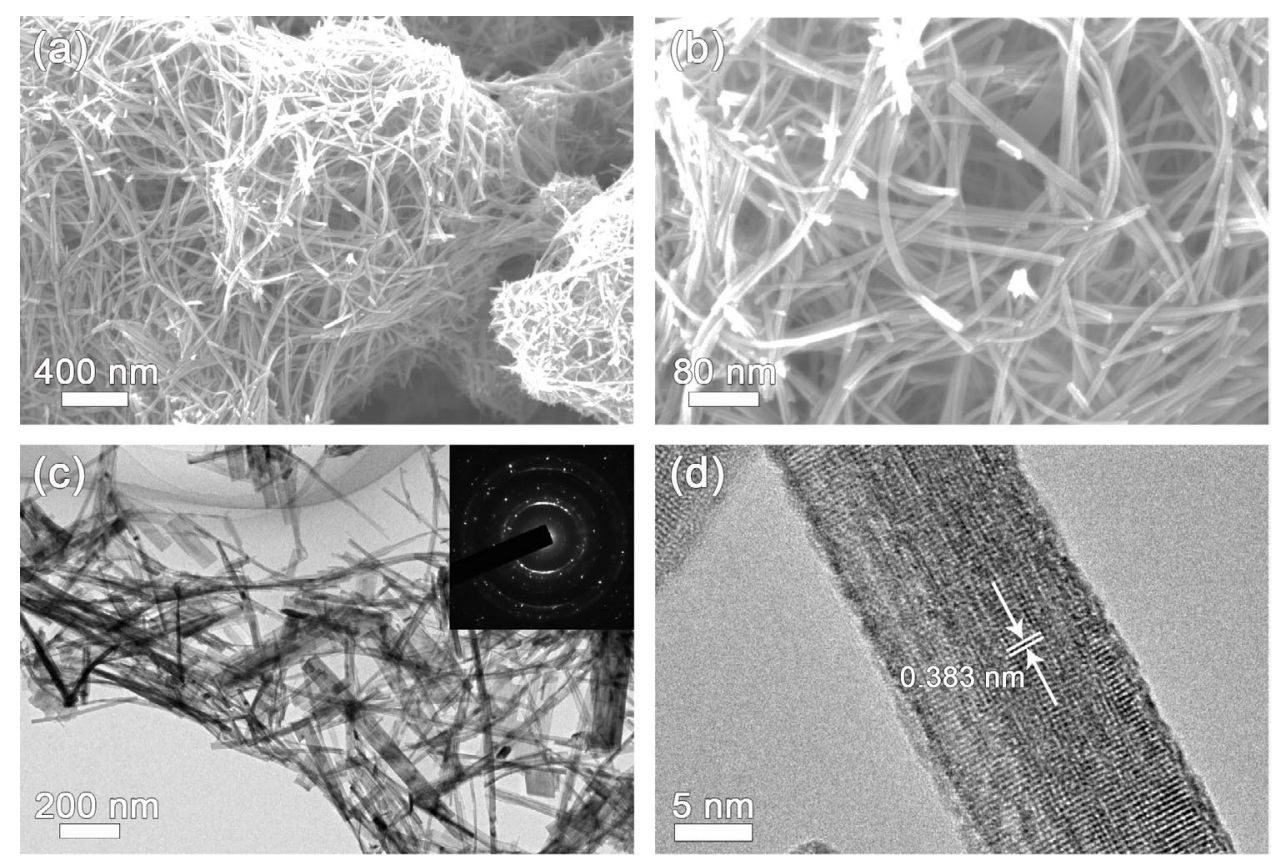

Fig. 4 SEM and TEM images of the annealed sample synthesized in precursor with $0.2 \mathrm{M} \mathrm{Tu}$. 
the high-magnification SEM images show the sample consists of nanowires forming a nanomesh morphology. Figure 4(c) shows the TEM image of interlaced nanowires, whose diameters are tens of nanometers and lengths are over several micrometres. The corresponding selected area electron diffraction (SAED) pattern (the inset in Fig. 4(c)) exhibits the diffraction rings, corresponding to the (100), (002), and (111) planes of hexagonal $\mathrm{WO}_{3}$. Figure 4(d) shows that the fringe interval of $0.383 \mathrm{~nm}$ agrees well with the $d$-spacing of (002) lattice planes perpendicular to the long axis of the nanowire.

The surface chemical state of the $\mathrm{WO}_{3}$ nanomesh was determined by XPS spectra. The C 1s peak of $284.8 \mathrm{eV}$ was used to calibrate all binding energies. Figure 5(a) shows the high-resolution XPS spectrum of the $\mathrm{O} 1 \mathrm{~s}$. The intense peak at $530.4 \mathrm{eV}$ can be assigned to lattice oxygen in $\mathrm{WO}_{3}$. Figure 5(b) shows the highresolution XPS spectrum of the $\mathrm{W} 4 \mathrm{f}$. The small peak at $41.5 \mathrm{eV}$ can be attributed to the $\mathrm{W} 5 \mathrm{p}_{3 / 2}$ of $\mathrm{WO}_{3}$ [17,33]. The two evident peaks at 35.5 and $37.7 \mathrm{eV}$, belonging to $\mathrm{W} 4 \mathrm{f}_{7 / 2}$ and $\mathrm{W} 4 \mathrm{f}_{5 / 2}$ of $\mathrm{WO}_{3}$, respectively, suggest that the tungsten oxide nanostructure exists as $\mathrm{W}^{6+}$ [34-36].

The structural and electronic properties of the $\mathrm{WO}_{3}$
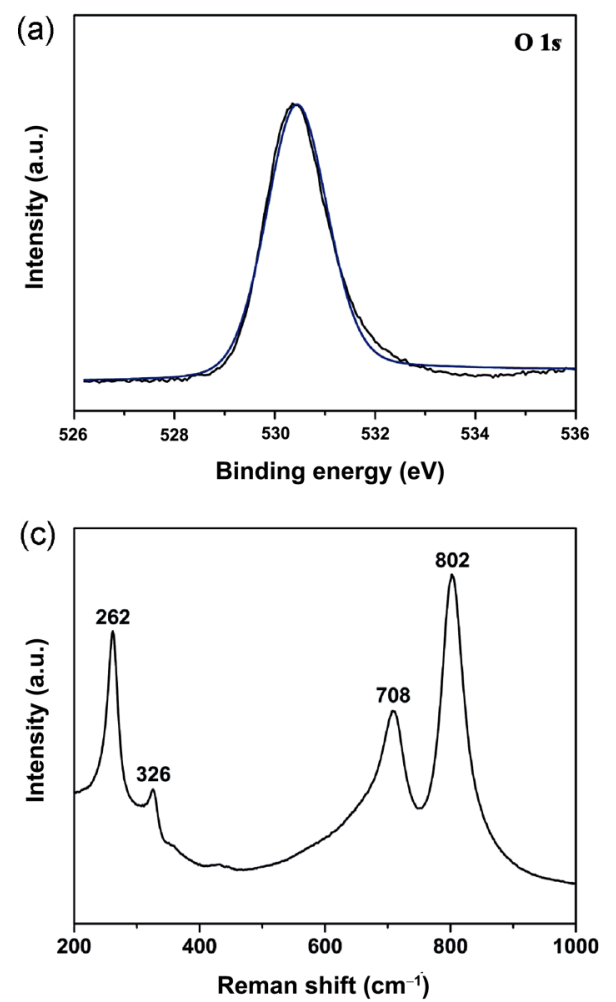

nanomesh were further characterized by Raman spectroscopy. As shown in Fig. 5(c), Raman peaks centered at about 262, 326, 708, and $802 \mathrm{~cm}^{-1}$ can be observed clearly, which can be assigned to the fundamental modes of hexagonal $\mathrm{WO}_{3}$ [37]. The sharp peaks located at about 262 and $326 \mathrm{~cm}^{-1}$ are assigned to the $\mathrm{W}-\mathrm{O}-\mathrm{W}$ bending mode; the evident peaks at about 708 and $802 \mathrm{~cm}^{-1}$ are attributed to the $\mathrm{O}-\mathrm{W}-\mathrm{O}$ stretching mode $[38,39]$. No peaks associated to impurities were observed indicating the high purity of the annealed $\mathrm{WO}_{3}$ nanomesh.

The specific surface area and pore-size distribution of the $\mathrm{WO}_{3}$ nanomesh were measured by the nitrogen adsorption/desorption isotherms, as shown in Fig. 5(d). The BJH pore size distribution (the inset in Fig. 5(d)) is widely distributed in the range of $1-135 \mathrm{~nm}$. The pores are mainly centered at $12.5 \mathrm{~nm}$, which arise from the space between nanowires. The BET surface area of the $\mathrm{WO}_{3}$ nanomesh is $104.3 \mathrm{~m}^{2} / \mathrm{g}$. In view of its large pore size and high exposed surface area, the $\mathrm{WO}_{3}$ nanomesh has great potential to show high gas-sensing performance.

\section{2 Gas sensing properties}

First, the response curves of the $\mathrm{WO}_{3}$ nanomesh sensor at different temperatures were measured. For the temperatures less than $160{ }^{\circ} \mathrm{C}$, the resistances of the sensor
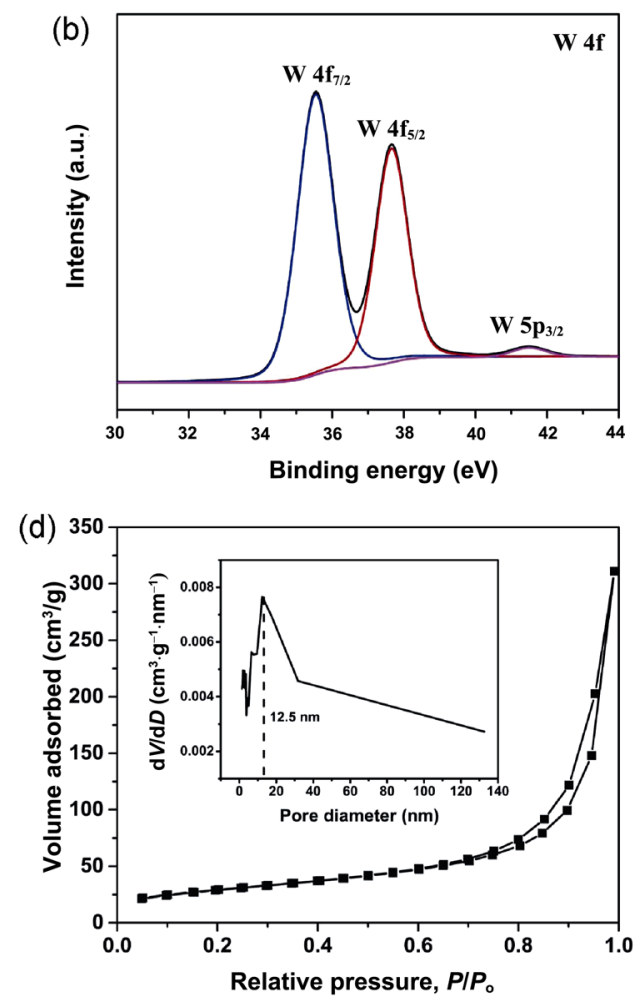

Fig. 5 (a) $\mathrm{O}$ 1s and (b) W 4 f region XPS spectra of the $\mathrm{WO}_{3}$ nanomesh; (c) Raman spectra of the $\mathrm{WO}_{3}$ nanomesh; (d) nitrogen adsorption/desorption isotherm and the corresponding BJH pore size distribution plots (inset) of the $\mathrm{WO}_{3}$ nanomesh. 
in $\mathrm{NO}_{2}$ gas was too large to measure by the multimeter. Therefore, the operating temperature of $160{ }^{\circ} \mathrm{C}$ or higher temperature was used in the gas-sensing tests.

The response of the $\mathrm{WO}_{3}$ nanomesh-based sensor to $500 \mathrm{ppb} \mathrm{NO}_{2}$ was measured at various operating temperatures. As shown in Fig. 6(a), the sensor response decreases as the temperature increases. Therefore, the optimal operating temperature of the $\mathrm{WO}_{3}$ nanomesh sensor is $160{ }^{\circ} \mathrm{C}$. Figure 6(b) shows the response and recovery time of the $\mathrm{WO}_{3}$ nanomesh sensor to $500 \mathrm{ppb}$ $\mathrm{NO}_{2}$ as a function of operating temperature. As the operating temperature increases, the response and recovery time of the sensor becomes shorter. These results indicate that the increase in temperature increases the adsorption and desorption rate of $\mathrm{NO}_{2}$ gas on the surface of $\mathrm{WO}_{3}$ namomesh. Figure 6(c) shows a typical dynamic response curve for $\mathrm{WO}_{3}$ nanomeshbased sensor to $\mathrm{NO}_{2}$ at a concentration ranging from 50 to $500 \mathrm{ppb}$ at an optimum operating temperature of $160{ }^{\circ} \mathrm{C}$. When the sensor is exposed to the oxidizing gas of $\mathrm{NO}_{2}$, its resistance increases; when the air is introduced, the resistance of the sensor returns to its original value. Figure 6(d) shows the relationship between the response of the $\mathrm{WO}_{3}$ nanomesh sensor and
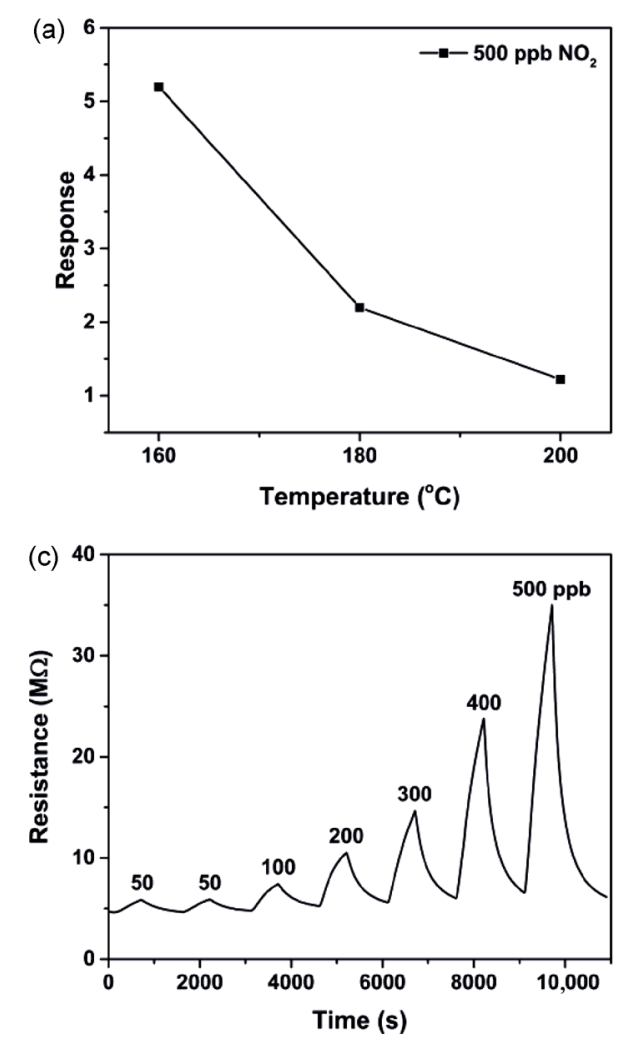

the $\mathrm{NO}_{2}$ concentration at $160{ }^{\circ} \mathrm{C}$. As the $\mathrm{NO}_{2}$ concentration increases from 50 to $500 \mathrm{ppb}$, the response of the sensor increases. Moreover, there is a relatively good linear relationship between response and $\mathrm{NO}_{2}$ concentration. This indicates that the $\mathrm{WO}_{3}$ nanomesh sensor has the advantage of detecting low concentrations of $\mathrm{NO}_{2}$. It is worth mentioning that the detection limit (LOD) of the $\mathrm{WO}_{3}$ nanomesh sensor is as low as $50 \mathrm{ppb}$.

Table 1 summarizes the comparison of $\mathrm{NO}_{2}$ sensing performance between $\mathrm{WO}_{3}$ nanomesh-based sensors fabricated in this work and other reported $\mathrm{WO}_{3}$ nanostructures. It is clear from Table 1 that the $\mathrm{WO}_{3}$ nanomesh material in this work exhibits the lowest detection limit at low operating temperature compared to other materials from Refs. [40-44]. In the absence of noble metal modification and ion doping, the intrinsic $\mathrm{WO}_{3}$ nanomesh material exhibits high response and very low detection limit at low operating temperature. There is no doubt that the $\mathrm{WO}_{3}$ nanomesh material prepared in this work is a competitive sensing material with good application prospects.

In order to evaluate the selectivity of the $\mathrm{WO}_{3}$ nanomesh-based sensor towards $\mathrm{NO}_{2}$ gas, sensing tests were also performed in other gases at the operating
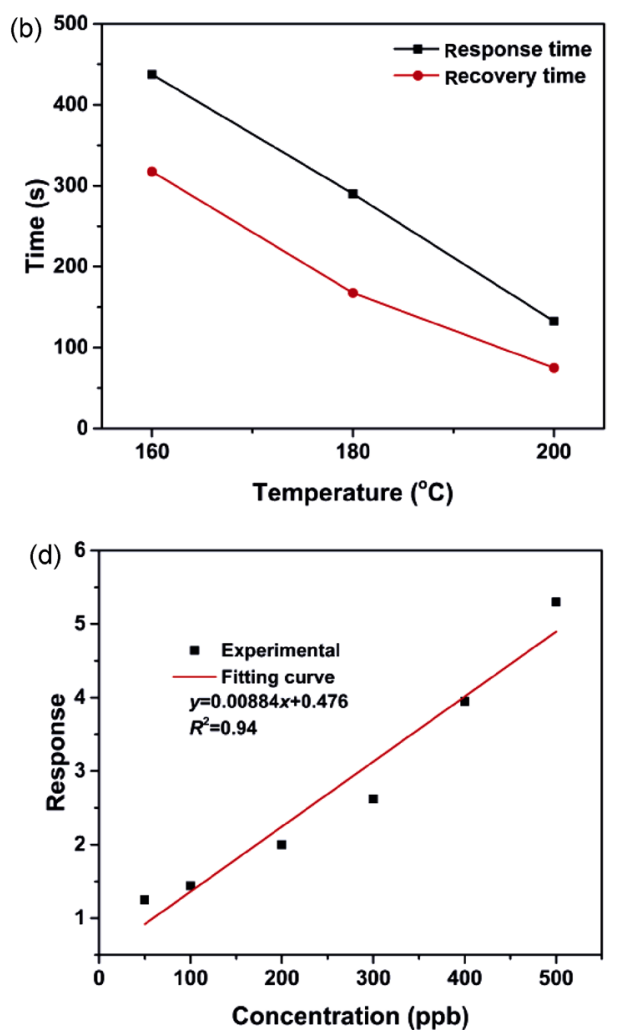

Fig. 6 (a) Response of $\mathrm{WO}_{3}$ nanomesh to $500 \mathrm{ppb} \mathrm{NO}$ as a function of operating temperature; (b) response and recovery time of $\mathrm{WO}_{3}$ nanomesh to $500 \mathrm{ppb} \mathrm{NO}$ as a function of operating temperature; (c) dynamic response of $\mathrm{WO}_{3}$ nanomesh toward $\mathrm{NO}_{2}$ gas at concentration ranging from 50 to $500 \mathrm{ppb}$ at $160{ }^{\circ} \mathrm{C}$; (d) correlation between the sensor response and $\mathrm{NO}_{2}$ concentration. 
Table 1 Gas sensing properties to $\mathrm{NO}_{2}$ in the present study and those reported in the literature

\begin{tabular}{|c|c|c|c|c|c|}
\hline Materials & Target gas & Low limit of detection & Temperature $\left({ }^{\circ} \mathrm{C}\right)$ & Response & Ref. \\
\hline $\mathrm{WO}_{3}$ nanowires & $\mathrm{NO}_{2}$ & $10 \mathrm{ppm}$ & 150 & 1.46 & {$[40]$} \\
\hline $\mathrm{WO}_{3}$ film & $\mathrm{NO}_{2}$ & $5 \mathrm{ppm}$ & 200 & 1.16 & [41] \\
\hline $\mathrm{WO}_{3}$ nanorods & $\mathrm{NO}_{2}$ & $2 \mathrm{ppm}$ & 200 & 1.5 & {$[42]$} \\
\hline $\mathrm{WO}_{3}$ nanotubes & $\mathrm{NO}_{2}$ & $1 \mathrm{ppm}$ & 300 & 1.44 & {$[43]$} \\
\hline Annealed $\mathrm{WO}_{3}$ nanorods & $\mathrm{NO}_{2}$ & $100 \mathrm{ppb}$ & 250 & 2 & {$[44]$} \\
\hline $\mathrm{WO}_{3}$ nanomesh & $\mathrm{NO}_{2}$ & $50 \mathrm{ppb}$ & 160 & 1.25 & Present study \\
\hline
\end{tabular}

temperature of $160{ }^{\circ} \mathrm{C}$. Figure 7 shows the response of $\mathrm{WO}_{3}$ nanomesh-based sensor to $\mathrm{NO}_{2}(500 \mathrm{ppb}), \mathrm{C}_{2} \mathrm{H}_{6} \mathrm{O}$ (10 ppm), $\mathrm{NH}_{3}(10 \mathrm{ppm}), \mathrm{CO}(50 \mathrm{ppm})$, and $\mathrm{H}_{2} \mathrm{~S}(5 \mathrm{ppm})$. It indicates that the $\mathrm{WO}_{3}$ nanomesh sensor has a significant response to $\mathrm{NO}_{2}$ compared to other gases, although the concentrations of other gases are higher. Therefore, it can be concluded that the prepared $\mathrm{WO}_{3}$ nanomesh sensor exhibits excellent selectivity to $\mathrm{NO}_{2}$. Repeatability and long-term stability are also important indicators for evaluating gas sensor performance. As shown in Fig. 8(a), the $\mathrm{WO}_{3}$ nanomeh-based sensor after 30 days of storage was used to test its cyclic response curve to $500 \mathrm{ppb} \mathrm{NO}_{2}$ at $160{ }^{\circ} \mathrm{C}$. It can be observed that the response curve of the sensor was excellent in repeatability, indicating good long-term stability of the sensor based on the $\mathrm{WO}_{3}$ nanomesh. The effect of humidity on the sensor response was investigated by comparing the $\mathrm{NO}_{2}$ sensing performance in dry air and humid air (produced by bubbling water). The response curve of the $\mathrm{WO}_{3}$ nanomesh-based sensor to $500 \mathrm{ppb} \mathrm{NO}_{2}$ under dry and humid conditions at $160{ }^{\circ} \mathrm{C}$ is shown in Fig. 8(b). Considering the margin of error, the response of the $\mathrm{WO}_{3}$ nanomesh sensor to $\mathrm{NO}_{2}$ is slightly reduced in a humid atmosphere. Therefore, it can be concluded that humidity has a small effect on the $\mathrm{NO}_{2}$ sensing characteristics of the $\mathrm{WO}_{3}$ nanomesh sensor.

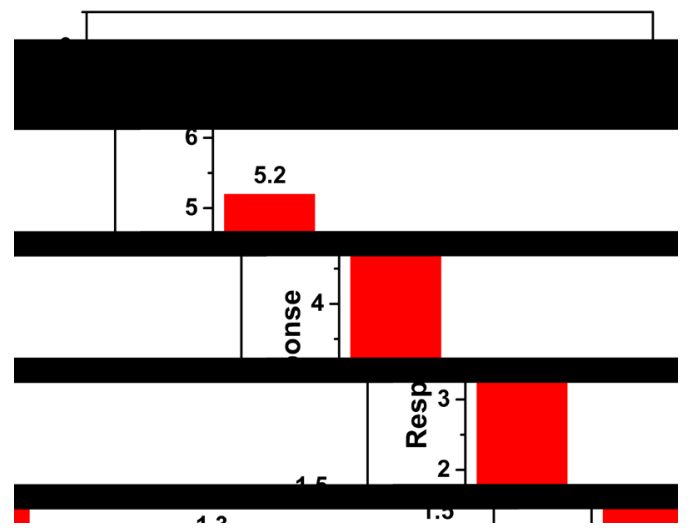

Fig. 7 Responses of $\mathrm{WO}_{3}$ nanomesh sensor to $\mathrm{NO}_{2}(500 \mathrm{ppb})$ and other several gas species such as $\mathrm{C}_{2} \mathrm{H}_{6} \mathrm{O}(10 \mathrm{ppm}), \mathrm{NH}_{3}$ (10 ppm), $\mathrm{CO}(50 \mathrm{ppm})$, and $\mathrm{H}_{2} \mathrm{~S}(5 \mathrm{ppm})$ at $160{ }^{\circ} \mathrm{C}$.
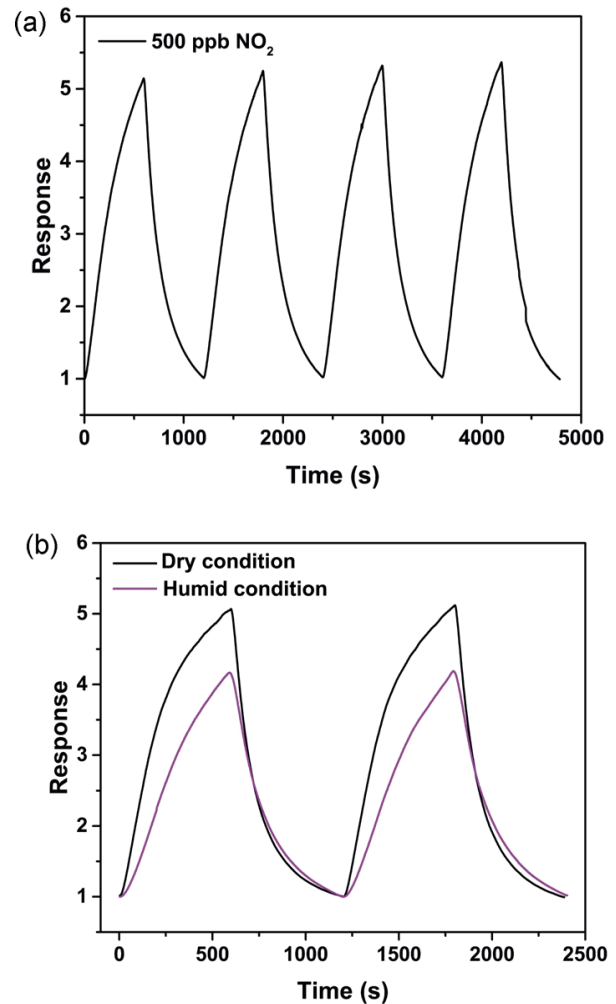

Fig. 8 (a) Cyclic response curve of $\mathrm{WO}_{3}$ nanomesh sensor after 30 days of storage to $\mathrm{NO}_{2}(500 \mathrm{ppb})$ at $160{ }^{\circ} \mathrm{C}$; (b) response curves of $\mathrm{WO}_{3}$ sensor to $\mathrm{NO}_{2}(500 \mathrm{ppb})$ at $160{ }^{\circ} \mathrm{C}$ in dry and humid condition.

\section{3 Gas sensing mechanism}

The electron depletion theory is well known to explain gas-sensing mechanisms by charge transfer between gas molecules and sensing materials [36,45]. Figure 9 shows the schematic diagram of $\mathrm{NO}_{2}$-sensing mechanism for $\mathrm{WO}_{3}$ nanomesh sensor. In air, oxygen molecules are adsorbed on the surface of $\mathrm{WO}_{3}$ nanomesh forming the adsorbed oxygen at low temperature $\left(<200{ }^{\circ} \mathrm{C}\right)$ as described in the following reaction:

$$
\mathrm{O}_{2} \text { (gas) }+\mathrm{e}^{-} \rightarrow \mathrm{O}_{2}^{-} \text {(ads) }
$$

Thus, an electron depletion layer is formed by reducing the free charge carrier consequently increasing 
(a)

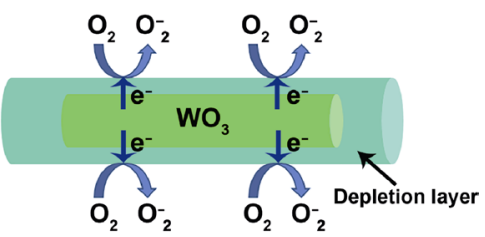

(b)

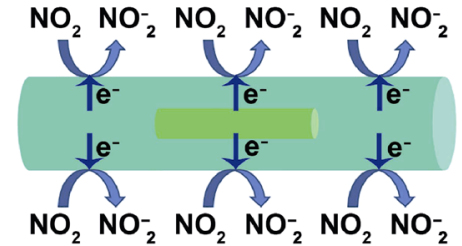

Fig. 9 Schematic diagram of gas-sensing mechanism for $\mathrm{WO}_{3}$ nanomesh sensor: (a) in air and (b) in air with $\mathrm{NO}_{2}$.

the resistance of the sensor. When $\mathrm{WO}_{3}$ nanomesh is exposed to oxidizing gas of $\mathrm{NO}_{2}, \mathrm{NO}_{2}$ molecule can easily capture electron from the surface of sensing material forming $\mathrm{NO}_{2}^{-}$as described in the following reaction:

$$
\mathrm{NO}_{2} \text { (gas) }+\mathrm{e}^{-} \rightarrow \mathrm{NO}_{2}^{-} \text {(ads) }
$$

Thus, a wider electron depletion layer is formed when $\mathrm{NO}_{2}$ is introduced and the resistance of the $\mathrm{WO}_{3}$ nanomesh increases. The $\mathrm{WO}_{3}$ nanomesh composed of $\mathrm{WO}_{3}$ nanowires can provide a higher specific surface area than conventional bulk materials, thereby providing more surface active sites for gas adsorption and improving $\mathrm{NO}_{2}$ sensing performance. Moreover, the high-purity single crystal nanowire assemblies promote rapid electron transfer and thus improve the gas sensing performance of $\mathrm{WO}_{3}$.

In order to verify the $\mathrm{NO}_{2}$-sensing mechanism proposed above, the responses of the $\mathrm{WO}_{3}$ nanomesh sensor to $\mathrm{NO}_{2}(500 \mathrm{ppb})$ in different backgrounds at $160{ }^{\circ} \mathrm{C}$ were measured. It can be shown in Fig. 10 that the

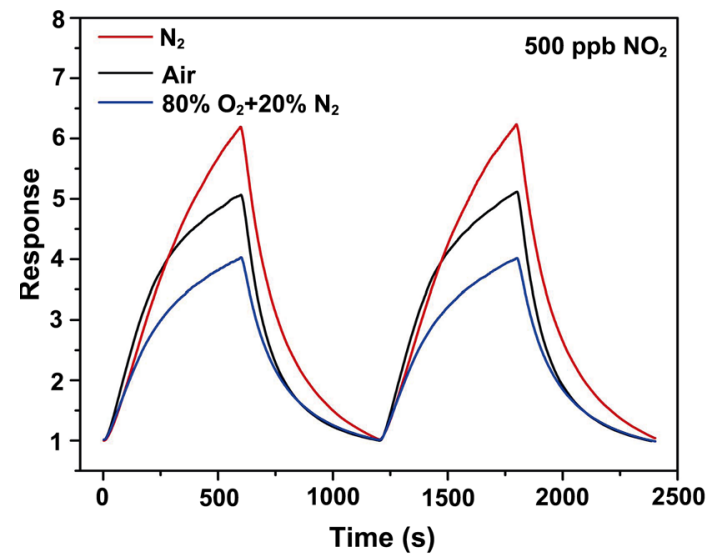

Fig. 10 Response curves of the $\mathrm{WO}_{3}$ nanomesh sensor to $\mathrm{NO}_{2}(500 \mathrm{ppb})$ in nitrogen balance and air balance, and $80 \% \mathrm{O}_{2}+20 \% \mathrm{~N}_{2}$ background at $160{ }^{\circ} \mathrm{C}$. response of the gas sensor decreases as the oxygen concentration in the background atmosphere increases. According to the above $\mathrm{NO}_{2}$-sensing mechanism, oxygen is not required when the $\mathrm{WO}_{3}$ nanomesh sensor detects $\mathrm{NO}_{2}$ gas. The $\mathrm{WO}_{3}$ nanomesh sensor has the same resistance when exposed to $\mathrm{NO}_{2}$ in different backgrounds. This means oxygen may not compete with $\mathrm{NO}_{2}$ gas for active sites on the $\mathrm{WO}_{3}$ nanomesh surface and therefore cannot affect the concentration of adsorbed $\mathrm{NO}_{2}$. This is why the sensor response $\left(R_{\mathrm{g}} / R_{\mathrm{a}}\right)$ decreases as the oxygen in the background gas increases.

\section{Conclusions}

Hierarchical $\mathrm{WO}_{3}$ nanomesh assembled from singlecrystalline $\mathrm{WO}_{3}$ nanowires was prepared via a hydrothermal method using $\mathrm{Tu}$ as a structure-directing agent and a morphology-controlling agent in the nucleation crystallization and assembly process. The interdigitated single crystal nanowires increase electron transfer so that the $\mathrm{WO}_{3}$ nanomesh has good conductivity and is suitable as a $\mathrm{NO}_{2}$-sensing material. The sensor based on $\mathrm{WO}_{3}$ nanomesh exhibits high response, fast response and recovery behavior, and excellent selectivity towards ppb-level $\mathrm{NO}_{2}$ at low temperature of $160{ }^{\circ} \mathrm{C}$. The excellent $\mathrm{NO}_{2}$-sensing performance may be primarily attributed to the large specific surface area of $\mathrm{WO}_{3}$ nanomesh and high purity nanowire assemblies improving gas absorption/desorption and electron transfer process. The prepared $\mathrm{WO}_{3}$ nanomesh material is a high-performance $\mathrm{NO}_{2}$ gas sensing material capable of working at low temperature, and therefore has a good application prospect. Our synthetic strategy towards hierarchical $\mathrm{WO}_{3}$ nanomesh with high gas sensitivity provides a way for developing high-performance gas sensor based on other wide-bandgap metal oxides.

\section{Acknowledgements}

The National Key Basic Research Program of China (973 Program) (No. 2013CB934301) supported this work.

\section{References}

[1] Afzal A, Cioffi N, Sabbatini L, et al. $\mathrm{NO}_{x}$ sensors based on semiconducting metal oxide nanostructures: Progress and perspectives. Sensor Actuat B: Chem 2012, 171: 25-42.

[2] Fine GF, Cavanagh LM, Afonja A, et al. Metal oxide semi- 
conductor gas sensors in environmental monitoring. Sensors 2010, 10: 5469-5502.

[3] Sukunta J, Wisitsoraat A, Tuantranont A, et al. $\mathrm{WO}_{3}$ nanotubes- $\mathrm{SnO}_{2}$ nanoparticles heterointerfaces for ultrasensitive and selective $\mathrm{NO}_{2}$ detections. Appl Surf Sci 2018, 458: 319-332.

[4] Wang ZY, Zhao C, Han TY, et al. High-performance reduced graphene oxide-based room-temperature $\mathrm{NO}_{2}$ sensors: A combined surface modification of $\mathrm{SnO}_{2}$ nanoparticles and nitrogen doping approach. Sensor Actuat B: Chem 2017, 242: 269-279.

[5] Minh Nguyet QT, van Duy N, Phuong NT, et al. Superior enhancement of $\mathrm{NO}_{2}$ gas response using n-p-n transition of carbon nanotubes $/ \mathrm{SnO}_{2}$ nanowires heterojunctions. Sensor Actuat B: Chem 2017, 238: 1120-1127.

[6] Geng $\mathrm{X}, \mathrm{Lu} \mathrm{PF}$, Zhang $\mathrm{C}$, et al. Room-temperature $\mathrm{NO}_{2}$ gas sensors based on $\mathrm{rGO} @ \mathrm{ZnO}_{1-x}$ composites: Experiments and molecular dynamics simulation. Sensor Actuat B: Chem 2019, 282: 690-702.

[7] Chen XX, Shen $\mathrm{YB}$, Zhou PF, et al. $\mathrm{NO}_{2}$ sensing properties of one-pot-synthesized $\mathrm{ZnO}$ nanowires with $\mathrm{Pd}$ functionalization. Sensor Actuat B: Chem 2019, 280: 151-161.

[8] Zhao SK, Shen YB, Zhou PF, et al. Design of $\mathrm{Au@} \mathrm{WO}_{3}$ core-shell structured nanospheres for ppb-level $\mathrm{NO}_{2}$ sensing. Sensor Actuat B: Chem 2019, 282: 917-926.

[9] Zhang ZY, Haq M, Wen Z, et al. Ultrasensitive ppb-level $\mathrm{NO}_{2}$ gas sensor based on $\mathrm{WO}_{3}$ hollow nanosphers doped with Fe. Appl Surf Sci 2018, 434: 891-897.

[10] Wang LL, Gao J, Wu BF, et al. Designed synthesis of $\mathrm{In}_{2} \mathrm{O}_{3}$ Beads@ $\mathrm{TiO}_{2}-\mathrm{In}_{2} \mathrm{O}_{3}$ composite nanofibers for high performance $\mathrm{NO}_{2}$ sensor at room temperature. ACS Appl Mater Interfaces 2015, 7: 27152-27159.

[11] González-Borrero PP, Sato F, Medina AN, et al. Optical band-gap determination of nanostructured $\mathrm{WO}_{3}$ film. Appl Phys Lett 2010, 96: 061909.

[12] Zheng HD, Ou JZ, Strano MS, et al. Nanostructured tungsten oxide-properties, synthesis, and applications. $A d v$ Funct Mater 2011, 21: 2175-2196.

[13] Korotcenkov G, Cho BK. Metal oxide composites in conductometric gas sensors: Achievements and challenges. Sensor Actuat B: Chem 2017, 244: 182-210.

[14] Kim DH, Jung JW, Choi SJ, et al. Pt nanoparticles functionalized tungsten oxynitride hybrid chemiresistor: Low-temperature $\mathrm{NO}_{2}$ sensing. Sensor Actuat B: Chem 2018, 273: 1269-1277.

[15] Isaac NA, Valenti M, Schmidt-Ott A, et al. Characterization of tungsten oxide thin films produced by spark ablation for $\mathrm{NO}_{2}$ gas sensing. ACS Appl Mater Interfaces 2016, 8: 3933-3939.

[16] Kim JS, Yoon JW, Hong YJ, et al. Highly sensitive and selective detection of ppb-level $\mathrm{NO}_{2}$ using multi-shelled $\mathrm{WO}_{3}$ yolk-shell spheres. Sensor Actuat B: Chem 2016, 229 : 561-569.

[17] Wang YL, Cui XB, Yang QY, et al. Preparation of Ag-loaded mesoporous $\mathrm{WO}_{3}$ and its enhanced $\mathrm{NO}_{2}$ sensing performance.
Sensor Actuat B: Chem 2016, 225: 544-552.

[18] Choi SJ, Lee I, Jang BH, et al. Selective diagnosis of diabetes using Pt-functionalized $\mathrm{WO}_{3}$ Hemitube networks as a sensing layer of acetone in exhaled breath. Anal Chem 2013, 85: 1792-1796.

[19] Xiong Y, Tang ZL, Wang Y, et al. Gas sensing capabilities of $\mathrm{TiO}_{2}$ porous nanoceramics prepared through premature sintering. J Adv Ceram 2015, 4: 152-157.

[20] Zhang HW, Wang YY, Zhu XG, et al. Bilayer Au nanoparticle-decorated $\mathrm{WO}_{3}$ porous thin films: On-chip fabrication and enhanced $\mathrm{NO}_{2}$ gas sensing performances with high selectivity. Sensor Actuat B: Chem 2019, 280: 192-200.

[21] Miller DR, Akbar SA, Morris PA. Nanoscale metal oxidebased heterojunctions for gas sensing: A review. Sensor Actuat B: Chem 2014, 204: 250-272.

[22] Jia QQ, Ji HM, Wang DH, et al. Exposed facets induced enhanced acetone selective sensing property of nanostructured tungsten oxide. J Mater Chem A 2014, 2: 13602.

[23] Shendage SS, Patil VL, Vanalakar SA, et al. Sensitive and selective $\mathrm{NO}_{2}$ gas sensor based on $\mathrm{WO}_{3}$ nanoplates. Sensor Actuat B: Chem 2017, 240: 426-433.

[24] Xiao BX, Zhao Q, Xiao CH, et al. Low-temperature solvothermal synthesis of hierarchical flower-like $\mathrm{WO}_{3}$ nanostructures and their sensing properties for $\mathrm{H}_{2} \mathrm{~S}$. CrystEngComm 2015, 17: 5710-5716.

[25] Jaroenapibal P, Boonma P, Saksilaporn N, et al. Improved $\mathrm{NO}_{2}$ sensing performance of electrospun $\mathrm{WO}_{3}$ nanofibers with silver doping. Sensor Actuat B: Chem 2018, 255 : 1831-1840.

[26] Wu QF, Huang J, Li H. Deposition of porous nano- $\mathrm{WO}_{3}$ coatings with tunable grain shapes by liquid plasma spraying for gas-sensing applications. Mater Lett 2015, 141: 100-103.

[27] Lee K, Baek DH, Na H, et al. Simple fabrication method of silicon/tungsten oxide nanowires heterojunction for $\mathrm{NO}_{2}$ gas sensors. Sensor Actuat B: Chem 2018, 265: 522-528.

[28] Zhang YJ, Zeng W, Li YQ. New insight into gas sensing performance of nanorods assembled and nanosheets assembled hierarchical $\mathrm{WO}_{3} \cdot \mathrm{H}_{2} \mathrm{O}$ structures. Mater Lett 2019, 235: 49-52.

[29] Zhai CB, Zhu MM, Jiang LN, et al. Fast triethylamine gas sensing response properties of nanosheets assembled $\mathrm{WO}_{3}$ hollow microspheres. Appl Surf Sci 2019, 463: 1078-1084.

[30] Lu J, Xu C, Cheng L, et al. Acetone sensor based on $\mathrm{WO}_{3}$ nanocrystallines with oxygen defects for low concentration detection. Mater Sci Semicond Process 2019, 101: 214-222.

[31] Zhang YX, Zeng W, Li YQ. $\mathrm{NO}_{2}$ and $\mathrm{H}_{2}$ sensing properties for urchin-like hexagonal $\mathrm{WO}_{3}$ based on experimental and first-principle investigations. Ceram Int 2019, 45: 6043 6050.

[32] Xue DP, Wang Y, Cao JL, et al. Improving methane gas sensing performance of flower-like $\mathrm{SnO}_{2}$ decorated by $\mathrm{WO}_{3}$ nanoplates. Talanta 2019, 199: 603-611. 
[33] Yin L, Chen DL, Hu MX, et al. Microwave-assisted growth of $\mathrm{In}_{2} \mathrm{O}_{3}$ nanoparticles on $\mathrm{WO}_{3}$ nanoplates to improve $\mathrm{H}_{2} \mathrm{~S}$-sensing performance. $J$ Mater Chem A 2014, 2: 18867-18874.

[34] Nayak AK, Ghosh R, Santra S, et al. Hierarchical nanostructured $\mathrm{WO}_{3}-\mathrm{SnO}_{2}$ for selective sensing of volatile organic compounds. Nanoscale 2015, 7: 12460-12473.

[35] Lee JS, Kwon OS, Shin $\mathrm{DH}$, et al. $\mathrm{WO}_{3}$ nanonoduledecorated hybrid carbon nanofibers for $\mathrm{NO}_{2}$ gas sensor application. J Mater Chem A 2013, 1: 9099.

[36] Shen YB, Wang W, Chen XX, et al. Nitrogen dioxide sensing using tungsten oxide microspheres with hierarchical nanorod-assembled architectures by a complexing surfactant-mediated hydrothermal route. $J$ Mater Chem A 2016, 4: 1345-1352.

[37] Daniel MF, Desbat B, Lassegues JC, et al. Infrared and Raman study of $\mathrm{WO}_{3}$ tungsten trioxides and $\mathrm{WO}_{3}, x \mathrm{H}_{2} \mathrm{O}$ tungsten trioxide tydrates. J Solid State Chem 1987, 67: 235-247.

[38] Zheng Y, Chen G, Yu YG, et al. Urea-assisted synthesis of ultra-thin hexagonal tungsten trioxide photocatalyst sheets. J Mater Sci 2015, 50: 8111-8119.

[39] Shi JJ, Cheng ZX, Gao LP, et al. Facile synthesis of reduced graphene oxide/hexagonal $\mathrm{WO}_{3}$ nanosheets composites with enhanced $\mathrm{H}_{2} \mathrm{~S}$ sensing properties. Sensor Actuat B: Chem 2016, 230: 736-745.

[40] Pan CT, Su CY, Luo YC. Study on comparing $\mathrm{WO}_{3}$ and $\mathrm{W}_{18} \mathrm{O}_{49}$ gas sensing abilities under $\mathrm{NO}_{2}$ environment. Microsyst Technol 2017, 23: 2113-2123.

[41] Mane AT, Kulkarni SB, Navale ST, et al. $\mathrm{NO}_{2}$ sensing properties of nanostructured tungsten oxide thin films.
Ceram Int 2014, 40: 16495-16502.

[42] Behera B, Chandra S. Synthesis of $\mathrm{WO}_{3}$ nanorods by thermal oxidation technique for $\mathrm{NO}_{2}$ gas sensing application. Mater Sci Semicond Process 2018, 86: 79-84.

[43] An S, Park S, Ko H, et al. Fabrication of $\mathrm{WO}_{3}$ nanotube sensors and their gas sensing properties. Ceram Int 2014, 40: $1423-1429$.

[44] Horprathum M, Limwichean $\mathrm{K}$, Wisitsoraat $\mathrm{A}$, et al. $\mathrm{NO}_{2}{ }^{-}$ sensing properties of $\mathrm{WO}_{3}$ nanorods prepared by glancing angle DC magnetron sputtering. Sensor Actuat B: Chem 2013, 176: 685-691.

[45] $\mathrm{Hu}$ J, Liang YF, Sun YJ, et al. Highly sensitive NO2 detection on ppb level by devices based on Pd-loaded $\operatorname{In}_{2} \mathrm{O}_{3}$ hierarchical microstructures. Sensor Actuat B: Chem 2017, 252: $116-126$.

Open Access This article is licensed under a Creative Commons Attribution 4.0 International License, which permits use, sharing, adaptation, distribution and reproduction in any medium or format, as long as you give appropriate credit to the original author(s) and the source, provide a link to the Creative Commons licence, and indicate if changes were made.

The images or other third party material in this article are included in the article's Creative Commons licence, unless indicated otherwise in a credit line to the material. If material is not included in the article's Creative Commons licence and your intended use is not permitted by statutory regulation or exceeds the permitted use, you will need to obtain permission directly from the copyright holder.

To view a copy of this licence, visit http://creativecommons.org/licenses/by/4.0/. 